1Mariela Dutra Gontijo MOURA. Professor. Department of Oral Surgery, Oral Medicine and Oral Pathology. School of Dentistry. Vale do Rio Verde University, Belo Horizonte, Brazil. dra mariela@hotmail.com

${ }^{2}$ Cristiano Mauro Assis GOMES Professor. Department of Psychology. School of Philosophy and Humanities. Federal University of Minas Gerais, Belo Horizonte Brazil.cristianogomes@gmail.com

`Silvia López de BLANC. Professor. Department of Oral Pathology. School of Dentistry. National University of Córdoba, Córdoba, Argentina lopesdeblanc2@gmail.com

4 Ricardo Alves MESQUITA. Professor. Department of Oral Surgery, Oral Medicine and Oral Pathology. School of Dentistry. Federal University of Minas Gerais, Belo Horizonte, Brazil. ramesquita@ufmg.br

${ }^{5}$ Efigênia Ferreira e FERREIRA Professor. Department of Socia Preventive Dentistry. School of Dentistry. Federal University of Minas Gerais, Belo Horizonte, Brazil. efigeniaf@gmail.com

Corresponding author: Dra. Mariela Dutra Gontijo Moura Faculty of Dentistry of UNINCOR Rua Nicaragua 120 Sion cep 30320050 BELO HORIZONTE-MG BRAZIL E-mail: dra.mariela@hotmail.com Telephone:(31) 99955-9222

Received: January 29, 2018 Accepted: August 06, 2018

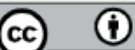

\section{Dentists' Perceptions of HIV/AIDS: psychometric properties of a first Questionnaire for Dentistry}

\author{
Mariela Dutra Gontijo Moura' ${ }^{1}$, Cristiano Mauro \\ Assis Gomes ${ }^{2}$, Silvia López de Blanc ${ }^{3}$, Ricardo Alves \\ Mesquita $^{4}$, Efigênia Ferreira e Ferreira ${ }^{5}$
}

Aim: The present study outlines the testing the first questionnaire to the field of dentistry to evaluate dentists' perceptions of HIV/AIDS, and its psychometric properties. Methods: A first questionnaire developed to evaluate dentists' perceptions of HIV/AIDS at this cross-sectional study contained 33 items in its original version. Randomly subsample of 251 Argentine dentists was invited to participate in the study. A four-factor structure (Transmission, Oral Manifestations, Dentists' practice, and Infection Controls) was tested through exploratory and confirmatory factor analysis, as well reliability was assessed. Results: The deletion of eight items from the original questionnaire improved the goodness of fit for the instrument. The retained 25 items revealed an acceptable reliability (internal consistency of 0.68 ), while the four factors revealed a Cronbach's al pha coefficient of 0.53 for Transmission factor items, 0.71 for Oral Manifestations factor items, 0.59 for Dentists' Practice factor items, and 0.48 for Infection Controls factor items. Higher scores were observed on the Oral Manifestations factor items, but convergent and discriminant validity was compromised for the others factors. Conclusions: The findings presented here demonstrate the value of this first questionnaire with 25 items as a starting point for further inquiry. However, it would be desirable to add more items and a replication of the questionnaire is suggested to determine the stability of its psychometric properties.

KeyWords:HIVinfections. Dental care.Acquiredimmunodeficiency syndrome. Health promotion. Surveys and questionnaires. 


\section{Introduction}

Most questionnaires have been developed and validated in English-speaking countries to identify and evaluate how oral problems interfere in people's quality of life ${ }^{1-4}$. Although questionnaires is also globally used for HIV AIDS, little is known about its use in dentists' perceptions, considering dentists as strategic professionals, with attitudes that can influence the behavior of other key components of the oral health care team ${ }^{5-8}$.

One of the most important challenges in successfully controlling the spread of HIV is mainly to control the discrimination ${ }^{9-11}$. AIDS-related discrimination mainly occurs on three areas: social and community area, medical and health work area and personal perception ${ }^{11-12}$. In the medical health care field, there are several main kinds of discrimination. For example, discriminatory treatment providing different treatment compared with other similar symptoms, refusal of treatment, and revealing infector's private information to the public or their family members ${ }^{11-13}$. Therefore, self-perceived medical discrimination can be comprehended as the awareness of actual or potential social rejection from medical workers and normal people ${ }^{11}$. There are no studies about discriminatory oral treatment in HIV/AIDS patients by dentists, it has become increasingly important to include in the research the knowledge of dental clinical practice to understand how dentists think of caring for HIV/AIDS patients to stimulate, in the future, studies about HIV/AIDS patients discriminatory treatment by dentists.

For this reason and because of the debilitating and unpredictable clinical course of HIV infection in all components of life, including oral health, there are many issues that currently stimulate interest in intercultural studies. So, the development a questionnaire to examine its psychometric properties as a new measure of identifying the primary care behavior of dentists in providing dental care offered to HIV/AIDS patients makes it possible to develop strategies to deal with HIV/AIDS 5-711,12,14-17. In the world literature, there are no studies like this for dentists, and the lack of such instruments in the world limits researchers ${ }^{5}$. Therefore, the present study outlines the testing the first questionnaire to the field of dentistry to evaluate dentists' perceptions of HIV/AIDS, and its psychometric properties.

\section{Materials and Methods}

The present study was carried out in the urban area of Córdoba, the capital city of the state of Córdoba, located in the central region of Argentina. The city has 1.5 million inhabitants and 2800 dentists. A list of all registered dentists was obtained from the School of Dentistry of State of Córdoba, Argentina.

By assessing the number of Argentine dentists, a standard error (SE) of $1 \%$ and a $99 \%$ confidence interval level were calculated for the study ( $n=250$ samples) with an expected prevalence of $50 \%{ }^{18}$. Data were collected from randomly subsample of 251 Argentine dentists of both genders, between 20 and 63 years of age. Only subjects who were treating patients at the time of the study were included in the study. 
Written informed consent was also obtained from all participants. The study was approved by the local ethical commission (report number 545/07-COEP).

A first questionnaire developed to evaluate dentists' perceptions of HIV/AIDS at this cross-sectional study contained 33 items in its original version ${ }^{5}$ (Figure 1). In previous study, test-retest reliability revealed stability of answers in a short time and satisfactory reproducibility $(\mathrm{ICC}=0.95)^{5}$.

A four-factor structure (Transmission, Oral Manifestations, Dentists' practice, and Infection Controls) was tested through exploratory and confirmatory factor analysis, as well reliability was assessed (Table 1).

Table 1. Cronbach's alpha coefficient and factorial loads of the items in exploratory and confirmatory factors analysis of the 25 items' questionnaire

\begin{tabular}{|c|c|c|c|c|c|}
\hline \multirow{2}{*}{$\begin{array}{l}\text { Items } \\
\text { Number } \\
\text { items }\end{array}$} & \multicolumn{5}{|c|}{ Factors of the Questionnaire } \\
\hline & $\begin{array}{l}\text { All questionnaire } \\
\text { (General factor) }\end{array}$ & $\begin{array}{l}\text { Transmission } \\
\text { (First order factor) }\end{array}$ & $\begin{array}{l}\text { Oral Manifestations } \\
\text { (First order factor) }\end{array}$ & $\begin{array}{c}\text { Dentists' } \\
\text { practice (First } \\
\text { order factor) }\end{array}$ & $\begin{array}{c}\text { Infection } \\
\text { Controls (First } \\
\text { order factor) }\end{array}$ \\
\hline 2 & -0.13 & 0.25 & & & \\
\hline 3 & 0.13 & 0.71 & & & \\
\hline 4 & 0.08 & 0.91 & & & \\
\hline 5 & 0.26 & & 0.04 & & \\
\hline 6 & 0.49 & & 0.05 & & \\
\hline 7 & 0.35 & & 0.12 & & \\
\hline 8 & 0.43 & & 0.27 & & \\
\hline 9 & 0.42 & & 0.46 & & \\
\hline 10 & 0.55 & & 0.05 & & \\
\hline 11 & 0.51 & & -0.20 & & \\
\hline 12 & 0.61 & & 0.00 & & \\
\hline 13 & 0.37 & & -0.21 & & \\
\hline 15 & 0.47 & & -0.38 & & \\
\hline 16 & 0.16 & & & 0.67 & \\
\hline 17 & 0.22 & & & 0.30 & \\
\hline 18 & 0.24 & & & 0.28 & \\
\hline 20 & 0.07 & & & 0.46 & \\
\hline 21 & 0.16 & & & 0.46 & \\
\hline 23 & 0.15 & & & 0.25 & 0.17 \\
\hline 25 & 0.14 & & & & 0.41 \\
\hline 26 & 0.16 & & & & 0.47 \\
\hline 27 & 0.10 & & & & 0.26 \\
\hline 28 & 0.05 & & & & 0.30 \\
\hline 29 & 0.01 & & & & 0.40 \\
\hline 33 & 0.12 & & & & 0.30 \\
\hline Alpha & 0.68 & 0.53 & 0.71 & 0.59 & 0.48 \\
\hline
\end{tabular}


The parallel analysis for permutation was used to extract the factors in exploratory factor analysis (EFA). The factors that were extracted were submitted to the rotation through the Oblique Minimum (oblimin) technique ${ }^{19}$. Inspection of the factorial loads of the items was carried out to show which items were contributing positively to the factors. The items with factorial loads lower than 0.2 were eliminated, because they were not collaborating with the necessary significant factorial loads to a factor. Valid factors were only those with at least three variables and with items of factorial load equal to or above $0.2^{19,20}$. A new EFA was carried out with the remaining items.

The confirmatory factor analysis (CFA) procedure was applied based on the one solution obtained through EFA. The criteria for satisfactory adjustment of the model to the data were adopted according to the following indices values: Comparative Fit Index (CFI) and Goodness of Fit Index (GFI) equal to or greater than 0.90, and Root Mean Square Residual (RMR) less than or equal to $0.08^{19,21}$. Ideal factorial loads for the general factor were considered to be equal to or greater than $0.3^{19}$.

Values for the internal consistency of this questionnaire were estimated by using Cronbach's Alpha Coefficient both for each isolated factor as for the general factor. Scales with reliabilities of at least 0.50 , but preferably 0.70 or greater, were considered sufficiently reliable to be used 22,23 .

The SPSS software program (version 16.0. SPSS Inc., Chicago, IL, USA) was used for the data analysis. Information was codified in a databank.

\section{Results}

The descriptive analyses showed the time of dentistry practice was from 1 to 40 year. The average years of practice was $11.4(S D=10.2)$. The researcher made sure that all dentists filled out completely the questionnaire.

The initial criterion, analyzed by parallel analysis for permutation, used to identify the number of factors of the questionnaire (Figure 1) resulted in the identification of four factors: Transmission factor with three items $(2,3,4)$; Oral manifestations factor with ten items $(5,6,7,8,9,10,11,12,13,15)$; Dentists' practice factor with six items $(16,17,18,20,21,23)$; and Infection Controls factor with seven items $(25,26$, $27,28,29,33$ ) (Figure 1).

Item 1 was excluded because all the dentists had answered positively that contaminated blood transmits the HIV/AIDS (Figure 1). Seven more items (items 14, 19, 22 , $24,30,31$ and 32 ) were excluded because the inspection of their factorial loads was problematic and they presented less than 0.2 factorial load. Thus, a satisfactory factor structure was obtained. Then, a new EFA was carried out and final result indicated the factor structure of the scale of 25 items the questionnaire.

In the analysis of first-order factors, correlations between these four first-order factors were identified: Transmission, Oral Manifestations, Dentists' practice, and Infection Controls factors. These correlations indicated the possibility of the scale of the questionnaire to show a factorial structure with the presence of a second-order general factor that was confirmed by the CFA model. The CFA model presented an adequate degree of adjustment to the data with RMR 0.05, GFI 0.927 and CFI 0.917. 


\begin{tabular}{lc}
\hline DK-HIV-Q & Domains \\
\hline By what means can HIV be transmitted? & \\
1. blood & 1 \\
2. saliva & \\
3. vaginal fluid & \\
4. semen &
\end{tabular}

What are the oral manifestations related to HIV/AIDS patients? Mark with an X (there can be more than one answer) any choice that you consider to be related.
5. Kaposi' s sarcoma
6. Oral hairy leukoplakia
7. Candidiasis
8. Necrotizing ulcerative gingivitis (ANUG)
10. Linear gingival erythema
11. Non-Hodgkin lymphoma
12. Herpes zoster
13. Parotid gland enlargement
14. Oral lichen planus
15. Condyloma acuminatum

Read the folowing. In this section, affirmative sentences are made. Mark with an $\mathrm{X}$ the option that you most identify with. Do not leave any options unchecked.

16. You are able to attend HIV/AIDS patient.

17. You have already treated an HIV/AIDS patient.

18. You know how to proceed when an occupational accident accurs.

19. After an occupational accident, you would do an analysis to verify the possibility of HIV infection.

20. You have adequate knowledge of infection control to prevent crss infection.

21. You need to receive special training on dental care to treat HIV/AIDS patients.

22. HIV/AIDS patients should be treated in an isolated environment or in specialized places.

23. You know the medicine most commonly used for HIV/AIDS patients.

24. You have already submitted an analysis to know if you are infected with HIV.

25. You have included some questions about HIV/AIDS in your dental records.

26. You often review dental records of your patients during dental care.

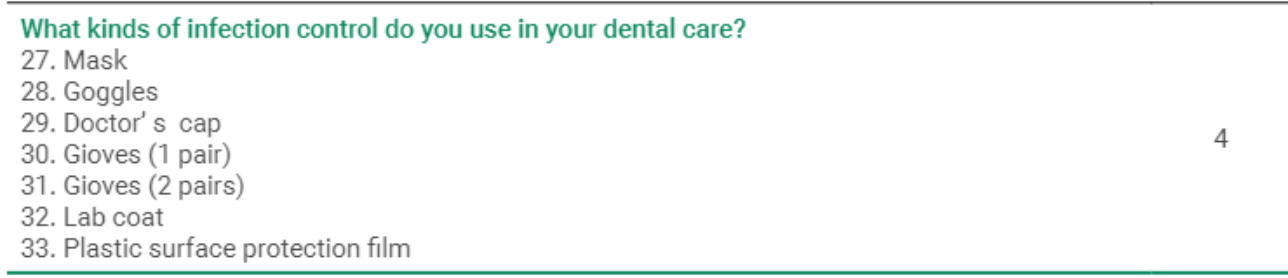

Figure 1. Dentists' knowledge of HIV/AIDS questionnaire (DK-HIV-Q) with 33 items

Table 1 presents factorial loads of the items of each four identified first-order factors, and the second-order general factor. Items with a factorial load of zero were omitted because they did not explain the factor by the dentists' answer to that item, and they were not related to the other factors (Table 1). The inspection of Table 1 allows us to verify that all factorial loads were adequate: above 0.20 for first-order factors, and above 0.30 for the second-order general factor.

All 25 items of the four second order factor had shown significant theoretical content about dentists' perceptions of HIV/AIDS. When the model factors were orthogonal by the CFA, the majority of items of Oral Manifestations factor $(6,7,10,11,12,13$ and 15) lost their specific quality and were more closely related to the general factor, because they presented a factorial load value above 0.30 for the general factor and below 0.20 for the Oral Manifestations factor (Table 1). However, Transmission, Dentists' practice, and Infection Controls factors were more specific, and they are not correlated to the general factor (Table 1). 
Internal consistency reliability was demonstrated by a Cronbach's Alpha coefficient for the four first order factors and for the second-order factor, and is also described in Table 1. Cronbach's Alpha for Oral Manifestations factor demonstrated satisfactory internal consistency. However, the other three factors presented low internal consistency, but the Cronbach's Alpha for the first order factor was 0.68 .

\section{Discussion}

In fact, to our knowledge this study is the first one to investigate the psychometric properties of the first questionnaire to the field of dentistry to evaluate dentists' perceptions of HIV/AIDS, because, in the worldwide literature, there are no studies such as that one for dentists ${ }^{5,16,24}$. The dentists' perceptions of HIV/AIDS would initially be dependent on knowledge and practice ${ }^{5,25}$. However, with repeated experience, specific routines for task performance can be set, with the triggering of procedural learning mechanisms. The contribution of knowledge about HIV/AIDS is dynamic and dependent on the amount of practice, rather than being a static characteristic of each type of knowledge ${ }^{25}$. It is important to highlight the difficulty of developing the psychometric properties of a new instrument to adequately addressed dentists' general perceptions of HIV/AIDS, and the influence of their knowledge of HIV/AIDS to understand how dentists think of caring for HIV/AIDS patients, mainly because of the difficulty to elaborate the correct questions for the first instrument. Furthermore, the findings from the current study revealed additional insights and details into the factor structure of this first questionnaire with a combined EFA and CFA approach.

In factorial analysis, defining the number of factors to extract is very important because the sub or super extraction may alter by any results of subsequent analysis $^{19,20,26}$. So, EFA of this current study revealed the existence of a four factor structure (Transmission, Oral Manifestations, Dentists' practice, and Infection Controls) and a general factor of second order. The presence of the second order factor contributed to the theoretical development of the field investigated and to the comprehension of the factorial structure of the central and peripheral elements of the instrument ${ }^{19,21}$. The concerns identified by the questionnaire were largely consistent with the dentists' perceptions of HIV/AIDS, and this evaluated construct is more adequately investigated in the version composed of 25 items. Deletion of the eight items that presented less than 0.2 factorial loads improved the goodness of fit for the instrument, by absence of relationship between the content of the items and the four factor structure. The exclusion of the item 14 in the Oral Manifestations factor was important and pertinent because the oral lichen planus is not a specific oral manifestation of patients with HIV/AIDS, so this does not show dentists' perceptions of HIV/AIDS. Also the items $19,22,24,30,31$ and 32 were shown not to be related to the dentists' perceptions of HIV/AIDS and were excluded. Smith and McCarthy ${ }^{26}$ (1995) emphasize that it is important to investigate the psychometric characteristics of items, especially if items are representing the content approached by the factor.

Clark and Watson ${ }^{27}$ (1995) describe medium correlation between items as a better indicator of the internal consistency than the alpha coefficient that is affected by the number of items. That can justify the attained Cronbach's Alpha coefficient of 0.53 for Transmission factors, 0.59 for Dentists' practice factors, and 0.48 for Infection 
Controls factors, representing, respectively, items 3, 6 and 7. It will be important in future studies to elaborate more items for each one of those three factors, because the Cronbach's Alpha coefficient was very low in this study. The subsequent addition of items for those three factors would improve the results and give a stronger and more consistent result. Low internal consistency coefficients for the first questionnaire sometimes would be found and, in those cases, may be related to the small number of items that composed factors ${ }^{23,24}$. This shortcoming is a problem that should be taken into account in the research. Values of the Cronbach's Alpha coefficient are sometimes between alpha $=0.42$ and $\mathrm{alpha}=0.64^{24}$. Some results of internal consistency are similar in Spanish ${ }^{24}$. Cortina ${ }^{23}$ (1993) shows that the alpha coefficient loses its usefulness in scales composed of more than 40 items.

However, Cronbach's Alpha coefficient was 0.68 for the total scale and 0.71 for Oral Manifestations factor, indicating adequate internal reliability, as reliability of at least 0.50 is acceptable but 0.70 and greater is preferable ${ }^{22,28}$. The item internal consistency is demonstrated when each item in a hypothesized scale is substantially linearly related to the underlying concept being measured ${ }^{22}$. The analysis also revealed that items majority of the Oral Manifestations factor present factorial loads greater than 0.30 for the general factor and less than 0.20 for the first order factor. The best factorial load would be above 0.4 to indicate the quality of the factorial solution factorial identified. Tabachnick and Fidel| ${ }^{28}(1996)$ propose the value of factorial load of 0.2 , preferably more than 0.3 , as the acceptable minimum for an item to be considered legitimately representative of the psychometric properties evaluated. Therefore, Oral Manifestations factor can be considered more representative of the psychometric properties of the dentists' perceptions of HIV/AIDS questionnaire, while items of Transmission, Dentists' practice, and Infection Controls factors do not contribute significantly to the dentists' perceptions of HIV/AIDS questionnaire. Nevertheless, if a new application of the questionnaire with construct validity of 25 items were given to the same sample, possibly the results would be different, maybe even better, and with stronger factorial loads.

With the increasing focus on AIDS, it is important for dentists to understand the value of having a common instrument for assessing multicultural labor forces when taking care of HIV AIDS patients $1,3,5,15,27,29-30$. The findings presented here demonstrate the value of this first questionnaire with 25 items, with satisfactory psychometric properties and consistent measurement tool, as a starting point for further inquiry. However, it would be desirable to add more items and a replication of the questionnaire is suggested to determine the stability of its psychometric properties.

\section{References}

1. Costa LS, Latorre MRDO, Hearst N, Marques HHS. Health Related Quality of Life Assessment questionnaire for children aged 5 to 11 years with HIV/AIDS: cross-cultural adaptation for the Portuguese language. Cad Saude Publica 2011;27(7):1445-9.

2. Herrmann S, McKinnon E, Hyland NB, Lalanne C, Mallal S, Nolan D, et al. HIV-related stigma and physical symptoms have a persistent influence on health-related quality of life in Australians with HIV infection. Health Qual Life Outcomes. 2013 Apr 8;11:56. doi: 10.1186/1477-7525-11-56. 
3. Pellegrino LA, Ortolan EV, Magalhaes CS, Viana AA, Narayanan UG. Brazilian Portuguese translation and cross-cultural adaptation of the "Caregiver Priorities and Child Health Index of Life with Disabilities" (CPCHILD) questionnaire. BMC Pediatr. 2014 Feb 1;14:30. doi: 10.1186/1471-2431-14-30.

4. Rai Y, Dutta T, Gulati AK. Quality of life of HIV-infected people across different stages of infection. J Happiness Stud. 2010 Mar;11(1):61-9.

5. Moura MDG, Gomes, CMA, Blanc SL, Mesquita RA, Ferreira EF. Development of questionnaire on dentists'knowledge of HIV/AIDS. Arq Odontol. 2014;50(1):6-12. doi: 10.7308/aodontol/2014.50.1.01.

6. Rungsiyanont S, Lam-Ubol A, Vacharotayangul P, Sappayatosok K. Thai dental practitioners'knowledge and attitudes regarding patients with HIV. J Dent Educ. 2013 Sep;77(9):1202-8.

7. Lemay CA, Cashman SB, McDonald A, Graves JR. A new approach to ensuring oral health care for people living with HIV/AIDS: the dental case manager. Prev Chronic Dis. 2012;9:E158. doi: $10.5888 /$ pcd9.110297.

8. WHO. Consolidated strategic information guidelines for HIV in the health sector. World Health Organization; 2015 [2018 Jun 12]. Available from: http://www.who.int/hiv/pub/guidelines/strategicinformation-guidelines/en/. English.

9. Abdool Karim Q. The global HIV epidemic: current status and challenges. Curr HIV/AIDS Rep. 2013 Jun;10(2):111-2. doi: 10.1007/s11904-013-0160-1.

10. Alfven $T$, McDougal L, Frescura L, Aran $C$, Amler P, Gill W. A decade of investments in monitoring the HIV epidemic: how far have we come? A descriptive analysis. Health Res Policy Syst. 2014 Oct 16;12:62. doi: 10.1186/1478-4505-12-62.

11. Pang M, Peng L, Zhang S, Yang J, Rao J, Wang H, et al. Medical Discrimination Affects the HIV/AIDS Epidemic Control: A Study of Self-Perceived Medical Discrimination on People Living with HIV or AIDS. Tohoku J Exp Med. 2017 Sep;243(1):67-75. doi: 10.1620/tjem.243.67.

12. Phillips $K D$, Moneyham $L$, Tavakoli A. Development of an instrument to measure internalized stigma in those with HIV/AIDS. Issues Ment Health Nurs. 2011;32(6):359-66. doi: 10.3109/01612840.2011.575533.

13. Templier J, Largeau C, Casadevall E, Berkaloff $C$. Protocol for the Identification of discrimination against people living with HIV. Geneva, Switzerland: UNAIDS; 2000.

14. Boileau C, Rashed S, Sylla M, Zunzunegui MV. Monitoring HIV risk and evaluating interventions among young people in urban West Africa: development and validation of an instrument. AIDS Educ Prev. 2008 Jun;20(3):203-19. doi: 10.1521/aeap.2008.20.3.203.

15. Patel S, Weiss E, Chhabra R, Ryniker L, Adsuar R, Carness J, et al. The events in care screening questionnaire (ECSQ): a new tool to identify needs and concerns of people with HIV/AIDS. AIDS Patient Care STDS. 2008 May;22(5):381-93. doi: 10.1089/apc.2007.0105.

16. Fogg CJ, Mawn BE, Porell F. Development of the Fogg Intent-to-Screen for HIV (ITS HIV) questionnaire. Res Nurs Health. 2011 Feb;34(1):73-84. doi: 10.1002/nur.20412.

17. Lemay CA, Kretsedemas M, Graves JR. Satisfaction with dental case management among people living with HIV/AIDS. J Community Health. 2010 Feb;35(1):43-52. doi: 10.1007/s10900-009-9195-z.

18. Kirkwood BR, Sterne JAC. Essentials of medical statistics. 2nd ed. Malden, Massachusetts: Blackwell Science; 2003 .

19. Reise SP, Waller NG, Comrey AL. Factor analysis and scale revision. Psychol Assess. 2000 Sep;12(3):287-97.

20. Thompson B. Guidelines for authors. Educ Psychol Meas. 1994;54(4):837-47.

21. McDonald RP, Ho MH. Principles and practice in reporting structural equation analyses. Psychol Methods. 2002 Mar; 7(1):64-82. 
22. Cronbach LJ. Coefficient alpha and the internal structure of tests. Psychometrika. 1951;16(3):297-334.

23. Cortina JM. What is coefficient alpha? An examination of theory and applications. J Appl Psychol. 1993;78(1):98-104.

24. Gil-Monte PR. Factorial validity of the Maslach Burnout Inventory (MBI-HSS) among Spanish professionals. Rev Saude Publica. 2005 Feb;39(1):1-8.

25. Can MM, Biteker M, Babur G, Ozveren O, Serebruany VL. Knowledge, attitude and perception of antiplatelet therapy among dentists in Central Eastern Turkey. World J Cardiol. 2012 Jul 26;4(7):22630. doi: $10.4330 /$ wjc.v4.i7.226.

26. Smith GT, McCarthy DM. Methodological considerations in the refinement of clinical assessment instruments. Psychol Assess. 1995;7(3):300-8. doi: 10.1037/1040-3590.7.3.300.

27. Clark AC, Watson D. Constructing validity: basic issues in objective scale development. Psychol Assess. 1995;7(3):309-19. doi: 10.1037/1040-3590.7.3.309.

28. Tabachnick BG, Fidell LS. Using multivariate statistics. 3rd ed. Nova York: HarperCollins; 1996.

29. Mussard J, Ashley FA, Newton JT, Kendall N, Crayford TJ. What do you think of your dentist? A dental practice assessment questionnaire. J Eval Clin Pract. 2008 Apr;14(2):181-4.

30. Civaner M, Arda B. Can "presumed consent" justify the duty to treat infectious diseases? An analysis. BMC Infect Dis. 2008 Mar 6;8:29. doi: 10.1186/1471-2334-8-29. 